\title{
Vitamin D deficiency and its correlation with pregnancy outcome
}

\author{
Maya Menon $^{1 *}$, Sridevi T. A. ${ }^{1}$, Thuthi Mohan ${ }^{2}$, Aruna B. Patil ${ }^{3}$
}

\author{
${ }^{1}$ Department of Obstetrics and Gynecology, ESIC Medical College and PGIMSR, K. K. Nagar, Chennai, Tamil Nadu, \\ India \\ ${ }^{2}$ Department of Biochemistry, ESIC Medical College and PGIMSR, K. K. Nagar, Chennai, Tamil Nadu, India \\ ${ }^{3}$ Department of Community Medicine, ESIC Medical College and PGIMSR, K. K. Nagar, Chennai, Tamil Nadu, India
}

Received: 30 January 2020

Accepted: 28 February 2020

\section{*Correspondence:}

Dr. Maya Menon,

E-mail: mayasree@gmail.com

Copyright: (C) the author(s), publisher and licensee Medip Academy. This is an open-access article distributed under the terms of the Creative Commons Attribution Non-Commercial License, which permits unrestricted non-commercial use, distribution, and reproduction in any medium, provided the original work is properly cited.

\section{ABSTRACT}

Background: There is a growing concern about the high prevalence of vitamin D deficiency and its relationship with variety of diseases worldwide. The objective of this study was to determine the prevalence of vitamin D deficiency and its association with pregnancy outcome.

Methods: This was a cross sectional study conducted among 150 antenatal women from October 2014 to April 2015. Data containing socio-demographic details, vitamin D level, serum calcium, pregnancy complications and growth situation of newborns were collected and analyzed.

Results: A total 150 pregnant women participated in the study, $75.3 \%$ were vitamin D deficient, $22.1 \%$ vitamin D insufficient and $2.6 \%$ normal. There was no significant adverse maternal outcome. NICU admission was required in 28.3 and $15.2 \%$ in the vitamin D deficient and insufficient groups respectively.

Conclusions: Women from different socioeconomic status, irrespective of parity and educational levels had vitamin $\mathrm{D}$ deficiency and insufficiency. This study fails to show a relation of vitamin D deficiency with other high-risk factors of pregnancy and does not show any adverse fetal outcome.

Keywords: Fetal outcome, Maternal outcome, Vitamin D deficiency

\section{INTRODUCTION}

Vitamin D also known as calciferol, is a prohormone that plays an important role in calcium homeostasis and bone health in addition to its neuromuscular functions. Vitamin D has two major forms, vitamin D2 and vitamin D3. Vitamin D in the skin should undergo hydroxylation in the liver (25OHD) hydroxylation in the kidney to 1,25 dihydroxy vitamin $\mathrm{D}$. This active form is required for absorption of calcium from gut and enables bone mineralization and growth. ${ }^{1}$

Severe vitamin D deficiency cause congenital rickets and fracture in new-born and disordered skeletal homeostasis. $25(\mathrm{OH}) \mathrm{D}$ is the main circulating vitamin $\mathrm{D}$ metabolite and its serum level serves as a biomarker of the vitamin status. ${ }^{2}$ High risks are vegetarians, limited sun exposure and ethnic minorities. Vitamin D (25 hydroxy D) is measured, normal $30 \mathrm{ng} / \mathrm{ml}$. IOM (institute of medicine) of nutritional academic recommend $600 \mathrm{IU} /$ day. Studies recommend 4,000 IU/day during pregnancy /lactation but experts recommend $1000-2000 \mathrm{IU} /$ day. $^{3}$ Vitamin D is a well-known determinant of bone health and correlated with a risk of many diseases such as cancers, cardiovascular diseases and diabetes. ${ }^{1}$ There is a growing concern about the prevalence of vitamin D deficiency worldwide including pregnant women.

Vitamin D deficiency is associated with bacterial vaginosis where there is loss of normal vaginal flora lactobacilli is replaced by anaerobic bacteria causing preterm labor, PROM, miscarriage, endometritis and 
wound infection. ${ }^{4}$ Vitamin D is essential to function of immune system, role it may play in bodies immunologic response to pathogens in the vagina. Pre-pregnancy obesity is associated with low level of vitamin D. ${ }^{5}$ Half an hour of sunlight delivers 5,000 IU Vitamin D. Maternal vitamin D level decreased in bacterial vaginosis, preeclampsia, gestational diabetes mellitus, preterm birth, fetal lung development, asthenia, rickets and small gestational age. ${ }^{6,7}$ The risk of vitamin D increases during pregnancy due to the increase in maternal and fetal demands. ${ }^{8}$ Indeed the WHO pregnancy guidelines clearly stated that vitamin $\mathrm{D}$ supplementation will probably have the most benefit in populations of poor countries, those with darker skin colour and in populations with a high prevalence of vitamin D deficiency. This is particularly relevant to the study population that tends to avoid sunshine, wear concealed clothing or use sunblock, all resulting in the low $25(\mathrm{OH}) \mathrm{D}$ levels observed across the life cycle. ${ }^{9}$

In developing countries, $18 \%$ of global burden of diseases has been related to pregnancy complications. Research shows Significant association between Vitamin D deficiency in pregnancy and elevated risk for preeclampsia, GDM and anemia. ${ }^{10}$ The prevalence of vitamin D deficiency has been an important issue in both developing and developed countries in recent years.

At present there are not many studies done to find an association between vitamin D deficiency and pregnancy outcome. Hence, the objective of this study was to determine the prevalence of vitamin D deficiency and its relationship with pregnancy and its maternal and fetal outcomes.

\section{METHODS}

This was a cross sectional study conducted among 150 pregnant women near term who were admitted in ESIC Hospital Chennai from October 2014 to April 2015. This study was conducted according to the guidelines laid down in the Declaration of Helsinki and all procedures involving human subjects were approved by the medical ethical committee of ESIC Medical college and PGIMSR, Chennai. The subjects provided written consent for participation in the study. The women were selected according to a non-proportionate sampling. All antenatal women at term irrespective of age and parity were included in the study. Antenatal women with chronic hypertension, Diabetes mellitus complicating pregnancy, hyperparathyroidism, thyroid disorders, kidney and liver disorders and those on antiepileptic drugs, vitamin D supplements were excluded.

Data about sociodemographic and personal details (age, education, occupation, gestational age, type of delivery), regular use of multivitamins during the current pregnancy and complications (preeclampsia, gestational diabetes, polyhydramnios, oligohydramnios, abortion, premature rupture of membrane during pregnancy and neonatal situation containing Apgar score, birth weight and neonatal admission.

Approximately, $5 \mathrm{ml}$ of whole blood was collected by venipuncture in a non-heparinized tube. The clotted blood was centrifuged and serum samples were stored at -80 degree centigrade until use. Serum concentration of 1,25 $(\mathrm{OH}) 2 \mathrm{D} 3$ was determined using an enzyme linked immunosorbent assay (ELISA) kit following the manufactures instructions. For the analysis, in this study, women were classified into groups that defined vitamin D status: $<20 \mathrm{ng} / \mathrm{ml}$ vitamin D deficiency, 20-30 $\mathrm{ng} / \mathrm{ml}$ vitamin $\mathrm{D}$ insufficient and $>30 \mathrm{ng} / \mathrm{ml}$ normal levels of vitamin D. ${ }^{6}$

\section{Statistical analysis}

Data were analyzed using SPSS version 20. Mann Whitney and Kruskal- Wallis were used to ascertain the significance of differences between mean values of continuous non normal distributed variables. Pearson's correlation coefficient was used to evaluate the strength association between two continuous variables after normalizing distributions using logarithm of these variables. All statistical tests were two sided, and $\mathrm{p}<0.05$ was considered statistically significant.

\section{RESULTS}

A total of 150 pregnant women participated in the study. Of them, 113 patients were vitamin D deficient, 33 vitamin D insufficient and 4 were normal. The percentage distribution of the pregnant women in the various groups is shown in Table 1. This study included Primi $(\mathrm{N}=67)$, gravida $2(\mathrm{~N}=62)$ and gravida $3(\mathrm{~N}=21) .34$ of the women had gestational age of 30-34 weeks, 120 were 34 -37 weeks and 6 of them were $>37$ weeks. The mean age of the women in the study was $(27.2 \pm 3.16) .50(44.2 \%)$ women in the vitamin D deficiency, $18(54 \%)$ in the insufficiency group had normal delivery. 39 (34.5\%) and $6(18.2 \%)$ had emergency LSCS.

Table 1: Vitamin D status of pregnant women in the study population.

\begin{tabular}{|l|l|l|l|}
\hline Groups & $\begin{array}{l}\text { Vitamin D } \\
\text { levels }(\mathbf{n g} / \mathbf{m l})\end{array}$ & $\mathbf{N}$ & $\%$ \\
\hline Vitamin D insufficient & $20-30$ & 33 & $22.1 \%$ \\
\hline Vitamin D deficient & $<20$ & 113 & $75.3 \%$ \\
\hline Normal & $>30$ & 4 & $2.6 \%$ \\
\hline
\end{tabular}

The maternal outcome in the different groups is shown in Table 2. $22.1 \%$ of the vitamin D deficiency patients and $27.9 \%$ of vitamin D insufficient group did not show any adverse maternal outcome. No statistically significant association was found in vitamin $\mathrm{D}$ deficient and insufficient groups $(\mathrm{p}<0.62)$.

Table 3 shows the fetal outcome in the three groups. 28.3 and $15.2 \%$ required NICU admissions in the vitamin D 
deficient and insufficient groups respectively. The results were not statistically insignificant with a $\mathrm{p}$ value of 0.66 .

Table 2: Maternal outcomes.

\begin{tabular}{|ll|ll|}
\hline $\begin{array}{l}\text { Maternal } \\
\text { outcomes }\end{array}$ & $\begin{array}{l}\text { Vitamin D } \\
\text { deficient }\end{array}$ & $\begin{array}{l}\text { Vitamin D } \\
\text { insufficient }\end{array}$ & Normal \\
\hline Anemia & $25(22.1 \%)$ & $6(18.25)$ & $2(50 \%)$ \\
\hline Oligo & $8(7.1 \%)$ & $1(3.0 \%)$ & $0(0.0 \%)$ \\
\hline PROM & $6(5.3 \%)$ & $1(3.0 \%)$ & $0(0.0 \%)$ \\
\hline Pre-eclampsia & $16(14.2 \%)$ & $3(9.1 \%)$ & $2(50 \%)$ \\
\hline GDM & $19(16.8 \%)$ & $12(36.4 \%)$ & $0(0.0 \%)$ \\
\hline $\begin{array}{l}\text { Pre-eclampsia } \\
\text { and GDM }\end{array}$ & $3(2.7 \%)$ & $0(0.0 \%)$ & $0(0.0 \%)$ \\
\hline $\begin{array}{l}\text { Bacterial } \\
\text { vaginosis }\end{array}$ & $8(7.1 \%)$ & $1(3.0 \%)$ & $1(3.0 \%)$ \\
\hline No risk & $25(22.1 \%)$ & $9(27.3 \%)$ & $0(0.0 \%)$ \\
\hline
\end{tabular}

Table 3: Fetal outcome.

\begin{tabular}{|c|c|c|c|}
\hline $\begin{array}{l}\text { Fetal } \\
\text { outcomes }\end{array}$ & $\begin{array}{l}\text { Vitamin D } \\
\text { deficient }\end{array}$ & $\begin{array}{l}\text { Vitamin D } \\
\text { insufficient }\end{array}$ & Normal \\
\hline $\begin{array}{l}\text { Low birth } \\
\text { weight }\end{array}$ & $79(70 \%)$ & $20(56 \%)$ & $2(50 \%)$ \\
\hline Apgar & $10(8.8 \%)$ & $2(6.1 \%)$ & $0(0.0 \%)$ \\
\hline NICU & $32(28.3 \%)$ & $5(15.2 \%)$ & $0(0.0 \%)$ \\
\hline
\end{tabular}

Mean serum calcium level was $8.6 \mathrm{mg} / \mathrm{dl}$ in vitamin D deficient group, $9.3 \mathrm{mg} / \mathrm{dl}$ in the vitamin $\mathrm{D}$ insufficient group and $10 \mathrm{mg} / \mathrm{dl}$ in the normal group. Despite high prevalence of hypovitaminosis D mean calcium level in all the groups were within the normal range.

\section{DISCUSSION}

Despite being in tropical country this study shows that there is prevalence of $75.3 \%$ of vitamin D deficiency. This is similar to previous studies in Yazd and other provinces of Iran that reported $64-75 \%$ of vitamin D deficiency in pregnant women. ${ }^{11}$ The most important source of vitamin D is the skins synthesis of the vitamin from sunlight. This vitamin is photosynthesized by ultraviolet B radiation in the epidermis. Use of sun blocks, increased coverage of clothing and time spent indoors increase the risk of vitamin D deficiency. ${ }^{12}$

Considering the diversity of factors which affect vitamin $\mathrm{D}$ level in different countries including sunshine exposure, wearing habits, diet, season of study, variation of vitamin D deficiency prevalence is expected. But though we are living in Chennai, southern India where it is hot throughout the year we found that the prevalence was high, the probable reason could be that people are staying indoors, working inside factories where they are not exposed to sunlight, study says that the sunlight exposure is best between $11 \mathrm{am}-3 \mathrm{pm}$ and most of the women are using sunscreen lotion which again reduces exposure to sunlight. The present study showed that there was $22.1 \%$ anaemia, $7.1 \%$ oligohydramnios, $5.3 \%$
PROM, 14.2\% HTN, 16.8\% GDM, 7.1\% $\quad$ BV. Oligohydramnios was seen in $<37$ weeks and it showed a significant risk.

However, no statistically significant relationship was found between vitamin D deficiency and other pregnancy problems, unlike other studies which reported various results in case of relationship between pregnancy problems and vitamin D deficiency.

Table 1 shows the prevalence of vitamin D deficiency was $75 \%$ in this study, Dave et al found a prevalence of 48 , Ates $\mathrm{S}$, found a prevalence of $45.9 \%$ in Turkey. ${ }^{1,4}$ Gupta $M$ et al, found a prevalence of $92.6 \%{ }^{5}$ Hypovitaminosis D has been reported to be $70.7 \%$ in southern part of India and $93.5 \%$ in northern India. ${ }^{13}$ Gupta D et al, showed $56 \%$ of prevalence from north eastern part of India. ${ }^{14}$ Despite abundant sunshine in the country, the high prevalence of vitamin D deficiency might be due to darker skin with melanin preventing the entry of ultraviolet rays in the skin, people remaining indoors, use of sunscreens, malabsorption, less exposure to sunshine, a vegetarian diet, less intake of calcium in the form of milk. In this study $22.1 \%$ showed insufficiency, $75 \%$ showed deficiency only $2.6 \%$ showed sufficient vitamin D level.

Table 2 shows the association of vitamin D deficiency and maternal outcome. Pre-eclampsia was noticed only $14.2 \%$ in this study, Dave et al, showed only 8 patients, Mamta et al, showed 31.5\%, Dipali et al $6.06 \%$, Bodnar et al showed a fivefold increased risk of pre-eclampsia in women with deficient vitamin D. ${ }^{1,2,5,15}$ On the contrary Shand et al, found no association between vitamin D deficiency and risk of pre-eclapmsia. ${ }^{16}$ Seda et al, also found no significant association between low vitamin D level and pre-eclampsia. ${ }^{4}$ The risk of glucose tolerance depends on the variations of ethnicity. Mamta et al, found women with severe deficiency developed GDM. ${ }^{5}$ Study done by Dave et al, reported number of gestational diabetes were less $(12.2 \%)$ and all had vitamin D deficiency. ${ }^{1}$ Sedas et al, did not show increased risk of GDM in vitamin D deficient. ${ }^{4}$ But Parlea et al, noted a two-fold increased risk of GDM in women with vitamin $\mathrm{D}<20-30 .{ }^{17}$ In this study, reported number of gestational diabetes was less $16.8 \%$ and all had vitamin D deficiency. This is a very small sample size to comment on the association of glucose tolerance and vitamin D deficiency.

A study in Turkey showed that $44.6 \%$ of pregnant women have vitamin D deficiency is associated with increased risk of Small for gestational age. ${ }^{4}$ In this study, low birth weight was $70 \%$ in deficient group. The variation in results between studies may also be explained by differences in cutoff points used, population characteristics, sample size and methods to measure 25 (OH)D. 
NICU admission was $28.3 \%$ showed no statistical significance in vitamin D deficiency group. Kazemi et al, found a significant difference in birth weight of babies of mothers who had higher vitamin D levels. ${ }^{18}$ Mothers with suboptimal vitamin D status have offspring with reduced intrauterine and postnatal skeletal development, but in study done by Mamta et al, mothers with babies having birth weight $>2.5 \mathrm{~kg}$ had a higher mean vitamin D level compared with mothers whose babies had birth weight $<2.5 \mathrm{~kg}$, though the difference was not statistically significant. ${ }^{5}$ Adequate nutritional vitamin D status during pregnancy is important for skeletal development, bone mineralization, tooth enamel formation and general fetal growth.

Merewood et al, study showed vitamin D deficiency has been associated with four-fold increased risk of primary caesarean section although this is not supported by all studies. $^{2}$ Dave et al, shows an association of vitamin D deficiency and caesarean deliveries $23.5 \%$ delivered by cesarean had vitamin D deficiency but this was not statistically correlated. ${ }^{1}$ In this study $34.5 \%$ in deficiency, $18.2 \%$ in insufficiency had undergone primary caesarean section. $44.2 \%$ in deficiency, 54\% in insufficiency group had normal vaginal delivery but this association is not statistically significant. Scholl et al, have found an association between vitamin D deficiency and caesarean section for prolonged labour. ${ }^{18}$ Though authors have given reasons that poor maternal vitamin $\mathrm{D}$ status is associated with poor muscle tone of pelvic floor and reduced pelvic muscle strength, reducing ability to push, these explanations are to be confirmed.

\section{CONCLUSION}

In this study, we found that women from all ages, socioeconomic status, irrespective of parity and educational levels had vitamin D deficiency and insufficiency.

This study shows high prevalence of vitamin D deficiency in pregnant women. Maternal complications like pre-eclampsia, GDM, preterm labour, PROM, oligohydramnios was not prominently seen in the deficient group and even fails to show direct relation with vitamin D deficiency and adverse neonatal outcome.

But many researchers are questioning the association of vitamin $\mathrm{D}$ deficiency and various medical disorder like hypertension, diabetes. Vitamin D deficiency and associated complications are seen very rarely in the individuals unless the deficiency is very severe.

Though there is a high prevalence of Vitamin D deficiency among the pregnant women, it has no relation to adverse maternal and fetal outcome.

To conclude, this study shows that the prevalence of vitamin $\mathrm{D}$ is $75 \%$ and the association between Vitamin D deficiency and adverse maternal and fetal outcome could not be established. Studies done on large population from different parts of the country are required to have a strong correlation.

\section{ACKNOWLEDGMENTS}

Authors would like to thank department of biochemistry for having helped us in the estimation of vitamin D.

Funding: No funding sources

Conflict of interest: None declared

Ethical approval: The study was approved by the Institutional Ethics Committee

\section{REFERENCES}

1. Prasad D, Smita, Singh K, Nisha S. Vitamin D in pregnancy and its correlation with feto maternal outcome. Inter J Cont Med Res. 2018;5(1):1-5.

2. Dave A, Verma M, Jain N. A study of vitamin D levels and associated deficiency in pregnancy and its effect on maternal and fetal outcome. Inter J Reprod Contracept Obstet Gynecol. 2017;6(1):84-8.

3. Merewood A, Mehta SD, Chen TC, Baucher H. Association between vitamin D deficiency and primary cesarean section. J Clin Endocrinol Metab. 2009;94(3):940-5.

4. Ates S, Sevket O, Ozcan P, Ozkal F. Vitamin D status in the first trimester: effects of vitamin D deficiency on pregnancy outcomes. Afri Health Sci. 2016;16(1):36-43.

5. Gupta M, Debnath A, Jain S, Saini V. Vitamin D status in pregnancy: fetomaternal outcome and correlation with cord blood vitamin D. Indian J Med Biochem. 2017;21(1):42-8.

6. Chen YH, Fu L, Hao JH, Wang H. Influent factors of gestational vitamin $\mathrm{D}$ deficiency and its relation to an increased risk of preterm delivery in Chinese population. Scientific Reports. 2018;8:3608.

7. Bener A, Al-Hamaq AO, Saleh NM. Association between vitamin D insufficiency and adverse pregnancy outcome: global comparisons. Inter J Womens Health. 2013;5:523-31.

8. Ghadeer K, Shaikh A, Ibrahim GH. Impact of vitamin $\mathrm{D}$ deficiency on maternal and birth outcomes in the Saudi population: a cross sectional study. BioMed Central Preg Childbirth. 2016;16:119.

9. Chakhtoura M, Nassar A, Arabi A, Cooper C. Effect of vitamin D replacement on maternal and neonatal outcomes: a randomized controlled trial in pregnant women with hypovitaminosis D. BMJ Open. 2016;6:e010818.

10. Movahedian A, Ghomian N, Soltani S. A review of the literature on the association between vitamin D status and the risk of pre-eclampsia. Rev Clin Med. 2015;2(1):15-8.

11. Pirdehghan A, Vakili M, Dehghan R. High prevalence of vitamin D deficiency and adverse pregnancy outcomes in Yazd, a central province of Iran. J Reprod Infertil. 2016;17(1):34-8. 
12. Kaushal M, Magon N. Vitamin D in pregnancy: a metabolic outlook. Indian $\mathrm{J}$ Endocr Metab. 2013;17:76-82.

13. Sharma S, Kumar A, Prasad S. Current scenario of vitamin D status during pregnancy in North India population. J Obstet Gynecol India. 2016;66(2):93100 .

14. Gupta DA, Saikia UK, Sarma D. Status of $25(\mathrm{OH}) \mathrm{D}$ level in pregnancy: a study from North eastern part of India. Indian J Endocrinol Metab. 2012;16(Supp1 2):S405-S407.

15. Bodnar LM, Catov JM, Simhan HN. Maternal vitamin $\mathrm{D}$ deficiency increases the risk of preeclampsia. J Clin Endocrinol Metab. 2007;92:3517-22.

16. Shand AW, Nassar N, Von Dadelszen P. Maternal vitamin $\mathrm{D}$ status $\mathrm{D}$ deficiency increases the risk of preeclampsia. BJOG. 2010;117(13):1593-8.

17. Parlea L, Bromberg IL, Feig DS, Vieth R. Association between serum 25-hydroxyvitamin D in early pregnancy and risk of gestational diabetes mellitus. Diabet Med. 2012;29:e25-e32.

18. Kazemi A, Sharifii F, Jafari N, Mousavinasab N. High prevalence of vitamin $\mathrm{D}$ among pregnant women and their newborn in an Iranian population. J womens Health (Larchmt). 2009;18:835-9.

19. Scholl TO, Chen X. Vitamin D intake during pregnancy. Association with maternal characteristics and infant birth weight. Early Hum Dev. 2009;85:231-4.

Cite this article as: Menon M, Sridevi TA, Mohan T, Patil AB. Vitamin D deficiency and its correlation with pregnancy outcome. Int J Reprod Contracept Obstet Gynecol 2020;9:1493-7. 